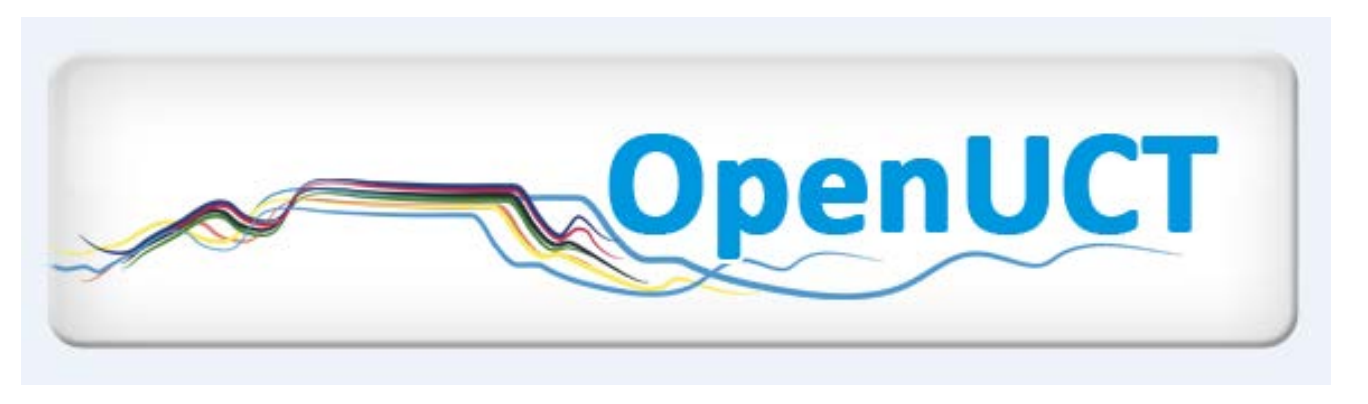

This is the post-print of Smith, L. \& Ranchhod, V. 2012. Measuring the impact of educational interventions on the academic performance of academic development students in second-year microeconomics. South African Journal of Economics. 80(3): 431-448.

It is made available according to the terms of agreement between the author and the journal, and in accordance with UCT's open access policy available: http://www.openuct.uct.ac.za/sites/default/files/UCTOpenAccessPolicy.pdf, for the purposes of research, teaching and private study. 


\title{
MEASURING THE IMPACT OF \\ EDUCATIONAL INTERVENTIONS ON THE \\ ACADEMIC PERFORMANCE OF ACADEMIC \\ DEVELOPMENT STUDENTS IN SECOND- \\ YEAR MICROECONOMICS
}

\author{
LEONARD C. SMITH* and VIMAL RANCHHOD**
}

\begin{abstract}
This paper analyses the impact of educational interventions made in the first- and second-year microeconomics courses on academic development students' final mark in the second-year course. It also addresses issues of methodology, specification, and statistical analysis with respect to other studies in the field. The results suggest that the educational interventions in the first-year had a positive impact on the academic performance of the academic development cohort, relative to the mainstream cohort for the first period (2000-2002). The results also suggest that the educational interventions introduced in the second period (2003-2005), in the form of voluntary workshops, improved the academic performance of the academic development and mainstream cohorts.
\end{abstract}

JEL Classification: I21

Keywords: academic development, academic performance, economic education, educational interventions, microeconomics, multivariate analysis, South Africa

\section{INTRODUCTION}

The poor academic performance of students at South African tertiary institutions is cause for concern and is reflected in low graduation rates across the sector (Scott et al. 2007). Of particular concern is the low graduation rate achieved by students who come from socially and educationally disadvantaged backgrounds. In response to this situation tertiary institutions have introduced a variety of academic development programmes and courses designed to enable such students to realise their full academic potential (Smith 2004).

The purpose of an academic development course in economics is to enable disadvantaged students to develop their learning, writing, quantitative and study skills, so that they are able to achieve success in a particular course and in subsequent courses in mainstream ${ }^{1}$ economics (Edwards 2000, Smith 2004, Smith and Edwards 2007, Smith

\footnotetext{
* Centre for Higher Education Development, University of Cape Town. Email: Leonard.Smith@uct.ac.za

** School of Economics, University of Cape Town. Email: vimal.ranchhod@gmail.com
} 
2009). In addition they are also designed to facilitate the students' understanding of the subject.

However, despite the use of educational interventions in economics and other courses at South African tertiary institutions, it is fair to say that relatively little research has been carried out to test the efficacy of these interventions in improving the performance of students doing academic development courses in economics (Edwards 2000, Smith 2004, Smith and Edwards 2007, Smith 2009).

The empirical aim of this study is to measure the impact of educational interventions in first- and second-year microeconomics courses on the academic performance of academic development students in the second-year mainstream microeconomics course (ECO2003F), relative to the performance of mainstream students.

We begin by estimating the effect of the educational interventions in the first-year academic development microeconomics course $(\mathrm{ECO} 1010 \mathrm{H})$ on students' academic performance in ECO2003F. Insofar as the academic performance of the ECO1010H cohort is improved, relative to mainstream students, it suggests that there may be lasting benefits that follow from the educational interventions included in the ECO1010H course. We also estimate the effect of voluntary workshops on the academic performance of the ECO1010H and mainstream cohorts doing ECO2003F. This exercise enables us to isolate the immediate benefit that may result from the educational interventions designed to enable students to deal with the particular difficulties they may encounter in ECO2003F.

Equally important in this paper is the methodology, specification, and statistical analysis used to ensure a robust set of results. In particular, specific attention is paid to addressing the sample-selection problem highlighted by Smith and Edwards (2007). They used the cohort for a single year to test the efficacy of an academic development course in first-year microeconomics on students' academic performance in the first-year course and in subsequent courses in macroeconomics and microeconomics, relative to a control group drawn from the mainstream, using the usual control variables. In the context of this paper the key finding was that students who did the academic development course in microeconomics out-performed the mainstream control group by an average of 12 percentage points for the structured/essay questions in the second-year microeconomics examination. ${ }^{2}$ This result suggests that the skills acquired in a first-year academic development course in microeconomics persist into further years.

The Smith and Edwards' (2007) study was characterised by a number of methodological problems, some of which this paper seeks to address, and in so doing it makes four advances to the existing empirical literature in this area. Firstly, each student is tracked until such time as they pass, withdraw from, or are excluded from ECO2003F. Secondly,

We would like to thank Corné van Walbeek, June Pym, Wiedaad Dollie, and four anonymous referees whose comments improved this paper. We also thank Fiona Gibbons for her patience in meeting our numerous requests for data. All errors are, of course, our responsibility.

1 "Mainstream" refers to those courses that make-up the standard three- and four-year degree programmes in the humanities and commerce faculties.

2 The data set for this estimation only included students who had passed the first-year course in 2001, and who wrote the final examination in second-year microeconomics the following year. 
this analysis is conducted for six cohorts including over 5000 observations covering the years 2000-2005; thus the effect of the interventions over the longer term is investigated. Thirdly, the Heckman two-part procedure is used to account for the sample-selection problem that arises as not all the students who start the course write the final examination. ${ }^{3}$ The larger sample size and the Heckman two-part procedure make it possible to generate a more robust set of results than is previously the case (Smith 2009). Finally, the effect of the educational interventions on the throughput rate for ECO2003F is calculated for the academic development cohort.

The structure of the paper is as follows. In Section 2 the academic development course in first-year microeconomics $(\mathrm{ECO} 1010 \mathrm{H})$ and the mainstream course in second-year microeconomics (ECO2003F) are described, as are the nature of the educational interventions. In Section 3 the empirical methodology and specification used in this paper is presented. Section 4 considers the data used and discusses the results, and Section 5 concludes the paper.

\section{CHARACTERISTICS OF THE ACADEMIC DEVELOPMENT AND MAINSTREAM COURSES IN MICROECONOMICS}

The academic development $(\mathrm{ECO} 1010 \mathrm{H})$ course in first-year microeconomics is described in Smith and Edwards' 2007 paper. In summary, the ECO1010H course includes short modules on quantitative techniques, graphical analysis and introductory macroeconomics in addition to the core first-year microeconomics course. The theoretical content of the microeconomics course mirrors that of the shorter singlesemester mainstream course in microeconomics (ECO1010F) and tests and examinations are set to the same standard.

There are several important differences between the academic development and mainstream courses with respect to the structure, content and teaching approach. The ECO1010H course runs over two semesters as opposed to a single semester, five lectures are offered per week as opposed to four, and classes are small (80 to 120 students) relative to the size of mainstream lecture groups (150 to 400 students). Greater emphasis is placed on using the tutorial system as a vehicle to develop students' metalearning skills. A weekly double-period (90 minute) language and communication tutorial is used to improve students' essay writing skills and their referencing and comprehension techniques. Students also take a double-period (90 minute) economics tutorial, where they are required to complete and submit written answers to a set tutorial made up of multiple-choice, paragraph/structured/essay, true/false, fill-in, calculation, and casestudy questions. The grades received for these assignments contribute towards their final mark. Tutors for both the economics and language and communication tutorials are chosen on the basis of their subject knowledge, their ability to facilitate learning and transmit knowledge, and on the degree of their commitment to enabling academic development students to make a success of their microeconomics course.

The ECO1010F economics tutorials pay less attention to the development of students' meta-learning skills. Each week, students attend a single-period (45 minute) tutorial during which various multiple-choice and structured/essay-type questions are discussed.

\footnotetext{
${ }^{3}$ See Parker (2007) and Smith (2009) for an explanation of how to use this procedure in a similar context.
} 
Students are required to submit written work less frequently and the grades for these assignments do not count towards their final mark. Further, no language and communication tutorials are offered. Tutors receive less training and support compared to those running the ECO1010H tutorials.

The assessment of the students undertaking the academic development course also differs from the mainstream course. In addition to the tutorials, students are required to complete three essays during the year, and write four tests in addition to the final examination. ${ }^{4}$ The tests include multiple-choice and structured/essay questions in the ratio of about 30 to 70 . In contrast, students in the mainstream economics courses are not required to submit essays and their tests consist solely of multiple-choice questions. ${ }^{5}$ Prior to 2003 (first period) ${ }^{6}$ academic development students who successfully completed ECO1010H went on to the second-year mainstream microeconomics course (ECO2003F) where they were left to "sink or swim". Starting in 2003 (second period) a fundamental change was made to the ECO2003F course. Although the content remained much the same 7 , a strong emphasis was placed on the use of mathematical techniques, rather than graphical analysis, to solve for equilibrium conditions under a variety of circumstances; for example, utility maximisation, cost minimisation and profit maximisation. Students were also expected to use calculus to solve the Cournot, Stackelberg and Bertrand oligopoly models.

In general, academic development students have a low level of mathematical ability as measured by their grades for mathematics and physical science in the matriculation examination. Therefore, it was decided to offer voluntary workshops to academic development students undertaking ECO2003F, which ran once a week for two hours. 177 academic development students, or $63.4 \%$ of the cohort, attended at least one of the voluntary workshops. ${ }^{8}$ Two activities predominated; the lecturer revised the key topics and concepts and students were led through a series of exercises, which gave them the opportunity to practise the key mathematical techniques.

In the following section we discuss the empirical methodology used to identify the extent to which the academic performance of the ECO1010H cohort doing ECO2003F is enhanced by the academic development course, ECO1010H. This enables us to identify the lasting benefit of the educational interventions incorporated in $\mathrm{ECO} 1010 \mathrm{H}$ on the academic performance of the ECO1010H cohort in ECO2003F. Further, we outline the empirical methodology used to determine the extent to which the introduction of workshops for students undertaking ECO2003F enabled them to improve their performance in second-year microeconomics. This makes it possible for us to identify the immediate benefit of the educational interventions offered to academic development students doing ECO2003F.

\footnotetext{
4 The final mark is made up as follows: three essays at $5 \%$ each $(15 \%)$, three tests at $5 \%$ each $(15 \%)$, one test at $10 \%, 20$ written economics tutorials $(5 \%)$ and the final examination $(55 \%)$. 5 The ECO1010F final mark is made up of the marks gained in two or three multiple-choice tests and the final examination. The tests count $45 \%$ of the final mark.

${ }^{6}$ The first period includes the cohorts for the years, 2000-2002, and the second period the cohorts for years, 2003-2005.

${ }^{7}$ Consumer demand theory, theory of the firm, market structure, labour markets, and welfare economics.

824 mainstream students also attended one or more of the voluntary workshops.
} 


\section{EMPIRICAL METHODOLOGY AND SPECIFICATION}

\section{(a) Specification}

The purpose of this paper is to test whether the educational interventions (discussed in the previous section) are effective in improving the academic performance of academic development students, and to refine the methodology and statistical analysis used to address the sample-selection problem. Observations are only included for $\mathrm{ECO} 1010 \mathrm{H}$ and ECO1010F students of the 2000-2005 cohorts, registered in the humanities and commerce faculties, and who wrote the South African matriculation examination. ${ }^{9}$ The cohorts for each of the first and second periods are pooled. International literature is followed to identify the conditional relationship between membership of ECO1010H and performance in ECO2003F; economics education is viewed as a production process whereby educational performance is a function of a variety of inputs (Edwards 2000). This relationship can be represented as:

\section{OUTPUT $=\mathrm{F}(\mathrm{D} 1010 \mathrm{H}$, STUDENT, MATRICULATION PERFORMANCE, SCHOOL, OTHER)

where:

OUTPUT is a measure of academic performance;

$\mathrm{D} 1010 \mathrm{H}$ is a dummy variable that equals 1 for the $\mathrm{ECO} 1010 \mathrm{H}$ cohort;

STUDENT includes variables measuring students' characteristics;

MATRICULATION PERFORMANCE includes variables measuring academic performance in school-leaving subjects;

SCHOOL includes the type of school attended;

OTHER includes other relevant variables such as faculty programme.

Multivariate analysis is used to estimate the effect of the educational interventions on the academic performance of the ECO1010H cohort relative to the ECO1010F cohort for both periods.

The first objective is to assess the effectiveness of the educational interventions incorporated in ECO1010H on students' academic performance in ECO2003F in the first period. This relationship is identified through the use of a dummy variable, $D$ $1010 \mathrm{H}$, which equals 1 for the $\mathrm{ECO} 1010 \mathrm{H}$ cohort. A positive sign for the coefficient of $D$ 1010H suggests that the educational interventions have a positive effect on ECO1010H students' academic performance relative to the mainstream cohort.

The second objective is to estimate the joint effect of the educational interventions in $\mathrm{ECO} 1010 \mathrm{H}$, and the ECO2003F workshops in the second period, on the academic performance of the ECO1010H cohort relative to the mainstream cohort. A positive sign for the coefficient of $D 1010 \mathrm{H}$ suggests that the educational interventions have a

\footnotetext{
${ }^{9}$ More than $95 \%$ of the ECO1010H students are South African citizens who wrote that country's matriculation examination, and more than $85 \%$ of them were registered in either the humanities or commerce faculties. To improve the match between the ECO1010H and ECO1010F cohorts, international students and students who wrote other matriculation examinations, and students from other faculties, are excluded.
} 
positive influence on ECO1010H students' academic performance relative to the mainstream cohort.

The third objective is to estimate the effect of the voluntary workshops on the academic performance of the academic development cohort in the second period. The number of workshops attended (WSHOP) is included as a continuous independent variable. A positive sign for the coefficient of this variable suggests that workshop attendance has a positive impact on the student's final mark in ECO2003F.

To obtain the conditional impact of ECO1010H on academic performance, a number of other variables that may explain students' academic performance in ECO2003F are included; variables for academic performance in school-leaving subjects, and course and student characteristics, which are selected on the basis of international and South African literature. ${ }^{10}$ These are listed in table 1 below and are now briefly discussed.

Proxies for academic preparedness are important in explaining students' academic performance at university. Following Edwards (2000) the matriculation points score calculated by the University of Cape Town ${ }^{11}$ as a measure of academic preparedness is adjusted as mathematics (HG), English first language (HG) and physical science (HG) are treated as independent variables. The points allocated to mathematics $(\mathrm{HG})$ and $(\mathrm{SG})$, English first language (HG), English second language (HG), and physical science (HG) are deducted from the matriculation points score to calculate the adjusted matriculation points score. Smith and Edwards (2007) report that the coefficient for the adjusted matriculation points score in the ECO2003F multiple-choice component of the final examination is 1.84 percentage points, and for the structured questions, 1.45 percentage points, and that both are statistically significant $(\mathrm{p}<0.01)$.

School-leaving subjects that are thought to capture students' ability, knowledge and skills that facilitate economics understanding are included as independent variables (Smith and Edwards 2007, Smith 2009). These include English first language (HG), mathematics (HG) and physical science (HG). The results for English are mixed; Smith and Edwards (2007) report that the coefficients for this variable, for the multiple choice and structured questions in the final ECO2003F examination, are statistically insignificant ( $p>0.05)$. Competence in mathematics is generally found to be strongly associated with academic performance in economics (Van Walbeek 2004, Parker 2006, Smith and Edwards 2007, Smith 2009). Smith and Edwards (2007) report a coefficient for mathematics (HG) of 6.0 percentage points, which is statistically significant $(\mathrm{p}<0.01)$, for the multiple-choice questions. Completion of physical science (physics and chemistry) has been shown to be positively correlated with economics understanding for South African students (Edwards 2000, Smith 2004, Van Walbeek 2004, Smith and Edwards 2007, Smith 2009) but to the authors' knowledge has not been analysed in the international literature. Smith and Edwards (2007) report coefficients of 6.75 and 3.84 percentage points (for physical science) for the multiple-choice and structured questions, respectively, in the final ECO2003F examination. Both coefficients are statistically significant $(\mathrm{p}<0.01)$.

\footnotetext{
${ }^{10}$ Edwards (2000), Van Walbeek (2004), Smith (2004), Van der Merwe (2006), Parker (2006), Parker (2007), and Smith and Edwards (2007).

11 The University of Cape Town allocates points to matriculation subjects in the following manner. Higher Grade: $A=8, B=7, C=6, D=5, E=4, F=3$. Standard Grade: Two points less for each symbol.
} 
Dummy variables, equal to 1, are included for English first language (HG) and physical science $(\mathrm{HG})$. For mathematics (HG) dummies are included for the symbol combinations $\mathrm{A}+\mathrm{B}+\mathrm{C}$ and $\mathrm{D}+\mathrm{E}+\mathrm{F}$.

Table 1. Control variables

\begin{tabular}{|c|c|c|c|c|c|c|}
\hline \multirow{4}{*}{ Cohort characteristics } & \multicolumn{3}{|c|}{$\begin{array}{l}\text { PERIOD } 1 \\
2000-2002\end{array}$} & \multicolumn{3}{|c|}{$\begin{array}{l}\text { PERIOD } 2 \\
2003-2005\end{array}$} \\
\hline & $1010 \mathrm{H}$ & $1010 \mathrm{~F}$ & Tests & $1010 \mathrm{H}$ & $1010 \mathrm{~F}$ & Tests \\
\hline & & & & & & \\
\hline & \multicolumn{2}{|c|}{$\%$ share $\%$ share } & z-test $\%$ & hare $\%$ sha & are $z$-test & \\
\hline Black & 55.6 & 16.7 & $15.6^{*}$ & 62.0 & 18.8 & $16.2^{*}$ \\
\hline Indian & 5.9 & 8.6 & 1.6 & 7.5 & 12.6 & $2.5^{*}$ \\
\hline Coloured & 22.2 & 11.8 & $5.1^{*}$ & 30.5 & 12.7 & $8.0^{*}$ \\
\hline White (White) & 16.3 & 62.9 & $15.4^{*}$ & 0.0 & 54.6 & \\
\hline English home language (Enghome) & 46.1 & 81.6 & $13.9^{*}$ & 35.8 & 79.1 & $15.8^{*}$ \\
\hline Male (Male) & 49.7 & 53.1 & 1.2 & 49.7 & 53.1 & $3.8^{*}$ \\
\hline \multirow[t]{2}{*}{ Commerce Faculty (Commerce) } & 53.6 & 96.2 & $24.4^{*}$ & 94.6 & 95.8 & 0.9 \\
\hline & Mean & Mean & t-test & Mean & Mean & t-test \\
\hline Age at entry (Age) & 18.3 & 18.6 & $4.7^{*}$ & 18.3 & 18.9 & $10.7 *$ \\
\hline School attended & $\%$ share & $\%$ share & z-test & $\%$ share & $\%$ share & z-test \\
\hline HRD (HRD) & 15.0 & 6.9 & $3.9^{*}$ & 17.6 & 6.2 & $6.9 *$ \\
\hline DET (DET) & 22.5 & 2.9 & $14.3^{*}$ & 24.7 & 3.8 & $14.1^{*}$ \\
\hline Matriculation points & Mean & Mean & t-test & Mean & Mean & t-test \\
\hline Mean matriculation points score (Matpt) & 32.4 & 40.9 & $34.6^{*}$ & 36.2 & 43.2 & $30.6^{*}$ \\
\hline $\begin{array}{l}\text { Mean adjusted matriculation points score } \\
\text { (Adjmatpt) }\end{array}$ & 21.5 & 27.5 & $32.4^{*}$ & 25.3 & 28.5 & $16.5^{*}$ \\
\hline Matriculation subjects & $\%$ share & $\%$ share & z-test & $\%$ share & $\%$ share & z-test \\
\hline $\begin{array}{l}\text { English first language (HG) } \\
\text { (Eng FL HG) }\end{array}$ & 71.6 & 94.9 & $13.6^{*}$ & 65.6 & 94.2 & $16.1^{*}$ \\
\hline Mathematics (HG) (Math HG) & 46.1 & 88.9 & $19.0^{*}$ & 67.7 & 92.8 & $13.4^{*}$ \\
\hline Physical science (HG) (PS HG) & 37.6 & 77.3 & $14.6^{*}$ & 41.6 & 76.9 & $12.7^{*}$ \\
\hline Observations & 306 & 2217 & & 279 & 2513 & \\
\hline
\end{tabular}

Note: * Statistically significant at the $1 \%$ level.

The column titled "Tests" provides the t- and z-statistics for the tests of equality of means and proportions between ECO1010H and ECO1010F students.

There are strong grounds for expecting English (home language) to have a positive impact on academic performance at universities where English is the medium of instruction (Edwards 2000) but for other South African studies the results are mixed (Parker 2006, Smith and Edwards 2007, Smith 2009). However, a dummy variable that equals 1 is included if the student's home language is English. Several studies report that males perform relatively well in multiple-choice questions and females in essay questions (Edwards 2000, Van Walbeek 2004, Smith and Edwards 2007, Smith 2009). For males, Smith and Edwards (2007) report coefficients of 2.06 percentage points (statistically significant $(\mathrm{p}<0.05)$ ) in the multiple-choice component of the ECO2003F examination and -2.57 percentage points (statistically significant $(\mathrm{p}<0.01)$ ) in the structured/essay questions component of the same examination. A dummy variable, equal to 1 if the student is male, is included.

Three variables are included that were absent from Smith and Edwards' (2007) study; student age at entry, school attended, and whether the student was previously classified as "white". It is suggested that there is a positive relationship between students" age and 
academic performance in economics; older students are more likely to have achieved the level of intellectual development necessary for mastering abstract processes (McConnell 1980). However, the evidence regarding students' ages is inconclusive (Park and Kerr 1990, Tay 1994, Van Walbeek 2004, Parker 2006, Smith 2009). Age is included as a continuous variable measured in years to the first decimal place.

Dummy variables, equal to 1, are included for each of the following types of school: schools that formerly fell under the Department of Education and Training (DET); and schools that formerly fell under the Houses of Representatives and Delegates (HRD). There is little evidence to suggest that students from former DET and HRD schools under-perform students from other schools and colleges (Edwards 2000, Smith 2004, Smith 2009) conditional on the usual range of independent variables.

A dummy variable, equal to 1 , is included for students previously classified as "white" on the grounds that many advantages accrued to members of the white population under the apartheid regime (Terreblanche 2002). These advantages make it more likely that white children in South Africa have access to material resources that are unavailable to other children. They are more likely to have parents who themselves have a tertiary qualification. Also, they are more likely to come from family backgrounds where it is expected that they will go to university. Smith (2009) reports a positive and statistically significant $(\mathrm{p}<0.01)$ coefficient of 3.43 percentage points (for white students) for the multiple-choice component of the first-year microeconomics examination.

Finally, many students attend the course more than once before they finally pass, fail or are excluded from the course. A continuous variable is included, which details the number of times each student attended the course.

\section{(b) Estimation issues and limitations}

The mainstream cohort (ECO1010F) can only act as a control group if it is drawn from the same population as the academic development cohort $(\mathrm{ECO} 1010 \mathrm{H}) \cdot{ }^{12}$ It may not be possible to make the assumption that students undertaking $\mathrm{ECO} 1010 \mathrm{H}$ and $\mathrm{ECO} 1010 \mathrm{~F}$ are drawn from the same population measured across a broad range of characteristics, both observable and unobservable. The difference in the academic performance of the ECO1010H cohort might be due to their differing set of characteristics rather than the effectiveness of the educational interventions embodied in the ECO1010H course. To test for the extent of the similarity between the two cohorts, differences of means and proportions tests were conducted for each of the continuous and discrete observable variables. The results are presented in table 1 above.

It is clear that the two cohorts differ markedly from one another; in nearly all cases the null hypothesis of equal means or proportions can be rejected. For example, the mean matriculation points score for the ECO1010F cohort is greater than the mean score for the ECO1010H cohort, and is statistically significant $(\mathrm{p}<0.01)$. The proportion of students with English as their home language is greater for the ECO1010F cohort, and black students make up a larger proportion of the ECO1010H cohort. Importantly, the ECO1010F cohort shows a strong bias towards mathematics (HG), English first

\footnotetext{
12 There is an extensive literature on sample-selection problems - this literature includes Park and
} Kerr (1990), and Raimondo, Esposito and Gershenberg (1990). 
language (HG) and physical science (HG). All these differences are statistically significant $(\mathrm{p}<0.01) .{ }^{13}$

In addition to the fact that the ECO1010F and ECO1010H differ markedly from one another as regards the observable variables there are three sample-selection issues that require consideration. The first is the selection process into ECO1010H. In general the students who do $\mathrm{ECO} 1010 \mathrm{H}$ do not have sufficient matriculation points to qualify for admission to the mainstream course, ECO1010F. However, the question remains; why do they opt to do an extended degree programme when they could gain entry to a mainstream programme at another university? In opting for the latter course of action they could expect to graduate earlier, and at less cost.

One possible explanation, for example, is that academic development students are more motivated to succeed. Unfortunately, we do not have the data to be able to answer this question and there is sufficient evidence to suggest that these traits are not stable over time (Bong 1996, Entwistle 1998). That said, insofar as students' level motivation is correlated with the treatment variable (academic development programme) its effect on academic performance may be erroneously attributed to the ECO1010H dummy variable.

The second issue is sample-selection into EC2003F. The data in respect of the throughput rates for the ECO1010H and ECO1010F cohorts are presented in table 2. In the first period $60.8 \%$ of the ECO1010H cohort and $60.7 \%$ of the ECO1010F cohort continued to do ECO2003F. In the second period the percentages are $78.2 \%$ and $88.7 \%$, respectively. Only the latter difference is statistically significant $(\mathrm{p}<0.01)$. It may be that the reasons for doing ECO2003F differ between the two cohorts. If that is the case we are faced with another sample-selection problem, for which we are unable to control. The presence of the unobservable variables that determine selection into ECO1010H and then into ECO2003F means that our results must be treated with some circumspection.

The third sample-selection problem arises once students have started ECO2003F. Not all students who start the course go on to write the final examination and complete the course. The main reason is that they do not meet the requirements to do so. For example, students are generally required to write all the tests, hand in a certain number of tutorial assignments, and attend a certain number of their tutorials. The exclusion of these students in the estimations may lead to sample-selection bias (Douglas and Sulock 1995, Parker 2006). This problem applies to both the ECO1010H and ECO1010F cohorts: $5.2 \%$ of the ECO1010H cohort and $2.0 \%$ of the ECO1010F cohort never wrote the final examination in the first period; and $5.4 \%$ of the $\mathrm{ECO} 1010 \mathrm{H}$ cohort and $2.0 \%$ of the ECO1010F cohort in the second period.

As previously noted the Heckman two-part procedure is used to account for the fact that not all students who started the course wrote the final examination. The first step is to construct a probit estimation to identify the importance of selected variables in

\footnotetext{
${ }^{13}$ Smith and Edwards (2007) used the cohort of students who were repeating the first-year microeconomics course in the second semester (ECO1010S) as a control group. However, in this study the performance of the ECO1010H cohort is compared to that of all the students who took the ECO1010F course in the first semester; it may be that the performance of the ECO1010S cohort in ECO2003F is negatively affected as they failed ECO1010F at their first attempt.
} 
explaining whether students wrote the final examination, or not. The variables included are age, schools, English as a home language, and whether the student was classified as "white" under the old dispensation. All these variables are discussed above. In addition a dummy variable, equal to 1 , is included if the student passed the first test. This is the unique (exclusion) variable used in the probit, but not in the multivariate, estimation. Older students, who were previously classified as "white", and who have English as their home language are expected to experience less difficulty in adapting to the academic demands made of them at university, and therefore, are more likely to write the final examination. Students who make a success of their first test are also deemed to be more likely to qualify for the final examination and complete the course. However, students from former DET and HRD schools are expected to be less likely to write the final examination and complete the course.

The result of the probit estimation is used to calculate the inverse Mills ratio (IMR), which is included as an additional explanatory variable in an OLS equation, which has the final mark as the dependent variable. The first test mark, however, is also included in the final mark. Therefore, we use an adjusted final mark, net of the test 1 mark, as the dependent variable in the Heckman OLS estimation. Thus the value of the dependent variable bears no relation to the value of the exclusion variable.

Multivariate analysis is used to control for the independent variables so as to isolate the effect of the educational interventions on the academic performance of the academic development cohort in second-year microeconomics course. That said, due consideration must be given to the sample-selection problems when interpreting the results.

\section{DATA AND RESULTS}

\section{(a) Analysis of data}

This section compares course performance, final course marks, and throughput rates for the $\mathrm{ECO} 1010 \mathrm{H}$ and ECO1010F cohorts for each of the two periods. The data are presented in table 2 .

Table 2. ECO2003F course performance, final course mark and throughput rates

\begin{tabular}{|c|c|c|c|c|c|c|}
\hline & \multicolumn{3}{|c|}{$2000-2002$} & \multicolumn{3}{|c|}{$2003-2005$} \\
\hline & $1010 \mathrm{H}$ & $1010 \mathrm{~F}$ & z-stat & $1010 \mathrm{H}$ & $1010 \mathrm{~F}$ & t-stat \\
\hline \multicolumn{7}{|l|}{ ECO2003F } \\
\hline Registered for ECO2003F & 306 & 2217 & & 279 & 2513 & \\
\hline Pass first time & 113 & 1674 & $13.9^{*}$ & 129 & 1898 & $10.4^{*}$ \\
\hline Percent pass first time & 36.9 & 75.5 & & 46.2 & 75.5 & \\
\hline Pass & 205 & 1987 & $11.0^{*}$ & 186 & 2318 & $13.3^{*}$ \\
\hline Percent pass & 67.0 & 89.6 & & 66.7 & 92.2 & \\
\hline Did not write final examination & 16 & 45 & $3.4^{*}$ & 15 & 51 & $3.6^{*}$ \\
\hline \multirow[t]{2}{*}{ Percent did not write } & 5.2 & 2.0 & & 5.4 & 2.0 & \\
\hline & & & t-stat & & & t-stat \\
\hline \multirow[t]{2}{*}{$\begin{array}{l}\text { Mean final mark (excluding those who did } \\
\text { not write final examination) }\end{array}$} & $50.6 \%$ & $58.7 \%$ & $12.7^{*}$ & $50.1 \%$ & $60.3 \%$ & $14.4^{*}$ \\
\hline & & & z-stat & & & z-stat \\
\hline Started ECO1010H/F & 503 & 2759 & & 357 & 2832 & \\
\hline Registered for ECO2003F & 306 & 1674 & & 279 & 2513 & \\
\hline Percent & 60.8 & 60.7 & 0.04 & 78.2 & 88.7 & $5.65^{*}$ \\
\hline Passed ECO2003F & 205 & 1987 & & 186 & 2318 & \\
\hline Percent & 40.8 & 72.0 & $13.7^{*}$ & 52.1 & 81.9 & $13.0^{*}$ \\
\hline
\end{tabular}

Note: * Statistically significant at the $1 \%$ level. 
The overall pass rate for ECO2003F is $89.6 \%$ for the ECO1010F cohort in the first period, which is 22.6 percentage points greater than that for the ECO1010H cohort. In the second period the difference is 25.5 percentage points. In both periods a greater proportion of the ECO $1010 \mathrm{H}$ cohort did not write the final examination, and a smaller proportion passed the course at the first attempt. Also, the ECO1010H cohort's mean final mark for ECO2003F is 8.1 percentage points lower than that achieved by the ECO1010F cohort in the first period and 10.2 percentage points lower in the second period. Finally, a much smaller proportion of the cohort who started ECO1010H passed ECO2003F relative to the ECO1010F cohort. These findings are not surprising given that the ECO1010H cohort has a lower level of academic preparedness as measured by their performance in the matriculation examination. However, the throughput rate for both the ECO1010H and ECO1010F cohorts improved in the second period. The improvement for the ECO1010H cohort is 11.3 percentage points and for ECO1010F, 9.9 percentage points.

\section{(b) Estimation results ${ }^{14}$}

The estimations use ordinary least squares (OLS) multivariate analysis to evaluate the impact of the academic development course $(\mathrm{ECO} 1010 \mathrm{H})$ and workshop attendance on students' academic performance in the second-year microeconomics course, relative to the mainstream (ECO1010F) cohort.

The results of the estimations for the first period are presented in table 3 below. As a first step only those students who wrote the final examination are included in the estimation (equation 1). The equation is estimated using the highest final course mark as the dependent variable and a selection of the variables in table 1 as explanatory, or independent, variables. Equations (2) and (3) are for the Heckman two-part estimation.

14 The statistical programme, STATA, is used for all the estimations. 
Table 3. Results of the OLS and Heckman two-part estimation for the first period (2000-2002)

\begin{tabular}{|c|c|c|c|c|c|c|}
\hline Variable & Base cases & $\begin{array}{c}\text { (1) } \\
\text { OLS }^{1}\end{array}$ & $\begin{array}{c}(1) \\
\text { Std Err }\end{array}$ & $\begin{array}{c}\text { (2) } \\
\text { Probit } \\
\text { WRITE }^{2}\end{array}$ & $\begin{array}{c}(3) \\
\text { OLS }^{3}\end{array}$ & $\begin{array}{c}(3) \\
\text { Std Err }\end{array}$ \\
\hline D $1010 \mathrm{H}$ & & $2.15^{*}$ & 0.84 & & 1.98 & 2.60 \\
\hline Adjmatpt & & $1.06^{* *}$ & 0.07 & & $0.94 * *$ & 0.21 \\
\hline D Eng FL HG & Eng SL HG & -1.53 & 0.98 & & -1.45 & 3.03 \\
\hline D Math HG ABC & Math SG & $2.67^{* *}$ & 0.60 & & 1.95 & 1.86 \\
\hline D Math HG DEF & Math SG & 0.02 & 0.25 & & 0.09 & 0.76 \\
\hline D PSHG & & $2.16^{* *}$ & 0.48 & & 1.71 & 1.50 \\
\hline Age & & -0.06 & 0.18 & -0.07 & 0.33 & 0.62 \\
\hline D Enghome & & 0.11 & 0.59 & -0.17 & 0.58 & 1.93 \\
\hline D Male & & 0.66 & 0.39 & & -0.43 & 1.23 \\
\hline D White & & $2.62 * *$ & 0.50 & 0.27 & 2.11 & 1.70 \\
\hline D HRD & & 1.01 & 0.77 & 0.00 & 1.24 & 2.52 \\
\hline D DET & & -0.40 & 1.10 & 0.06 & -0.07 & 3.54 \\
\hline D Commerce & & -0.35 & 0.77 & & -0.57 & 2.39 \\
\hline Course repeated & & $-1.09 * *$ & 0.38 & & 1.08 & 1.22 \\
\hline D Pass Test 1 & & & & $0.88^{* *}$ & & \\
\hline D Year 2001 & 2000 & 0.25 & 0.51 & & 0.72 & 1.60 \\
\hline D Year 2002 & 2000 & $-1.19 *$ & 0.52 & & -2.84 & 1.65 \\
\hline IMR & & & & & -30.3 & 16.0 \\
\hline Constant & & $28.3^{* *}$ & 4.46 & $2.92^{* *}$ & 25.7 & 14.3 \\
\hline $\mathrm{R}^{2}$ & & 0.246 & & & & \\
\hline F-stat. & & $49.8^{* *}$ & & & & \\
\hline Wald $\mathrm{Chi}^{2}$ (16) & & & & & $56.4^{* *}$ & \\
\hline Observations & & 2462 & & 2523 & 2462 & \\
\hline
\end{tabular}

Notes:

1 OLS estimation excluding students who did not write the final examination.

2 Probit estimation for the first part of the Heckman two-part procedure.

3 OLS estimation for the second part of the Heckman two-part procedure.

** and $*$ Statistical significance at $1 \%$ and 5\% levels, respectively.

Equation 1 reveals that the ECO1010H cohort (D 1010H) out-perform their peers on the mainstream by 2.15 percentage points, on average, conditional on the explanatory variables, and is statistically significant $(\mathrm{p}<0.05)$. Equation $(2)$ has a binary dependent variable, WRITE, (did write the final examination). It is estimated to identify the importance of the selected variables in explaining whether students wrote the final examination or not. The result of this estimation is used to calculate the inverse Mills ratio (IMR), which is included as an additional explanatory variable in equation (3). The coefficient for the ECO1010H dummy is 1.98, but is statistically insignificant (equation 3) $(p>0.10)$. The chief reason for the statistical insignificance of this, and the other variables in this estimation, is that the standard error for these variables is very much greater than they are in equation 1.

Together the results of equations (1) and (3) suggest that the educational interventions, designed primarily to improve ECO1010H students quantitative, comprehension and writing skills in first-year microeconomics, also improved their performance in ECO2003F, where assessment is conducted using multiple-choice and structured questions in tutorials, tests and examinations.

We also included two quadratic terms, Adjmatpt $t^{2}$ and $A G E^{2}$ to establish the returns to age and academic ability, as measured by the adjusted matriculation points score. The returns to academic ability are positive and statistically significant $(\mathrm{p}<0.01)$, although the 
coefficient is very small (0.07). The returns to age are positive, but statistically insignificant $(\mathrm{p}>0.10)$.

The results for the same set of estimations in respect of the second period are presented in table 4. The variable for workshop attendance is excluded as we wish to estimate the effect of the educational interventions in both the first- and second-year microeconomics courses on the academic performance of the $\mathrm{ECO} 1010 \mathrm{H}$ cohort in $\mathrm{ECO} 2003 \mathrm{~F}$.

Table 4. Results of the OLS and Heckman two-part estimation for the second period without workshops

\begin{tabular}{|c|c|c|c|c|c|c|}
\hline Variable & Base cases & $\begin{array}{l}\text { (1) } \\
\text { OLS }\end{array}$ & $\begin{array}{c}(1) \\
\text { Std Err }\end{array}$ & $\begin{array}{c}(2) \\
\text { Probit } \\
\text { WRITE }\end{array}$ & $\begin{array}{c}(3) \\
\text { OLS }^{3}\end{array}$ & $\begin{array}{c}(3) \\
\text { Std Err }\end{array}$ \\
\hline D $1010 \mathrm{H}$ & & -1.43 & 0.81 & & -1.63 & 1.29 \\
\hline Adjmatpt & & $0.94^{* *}$ & 0.07 & & $0.98^{* *}$ & 0.12 \\
\hline D Eng FL HG & Eng SG FL & 0.19 & 1.02 & & 0.64 & 1.65 \\
\hline D Math HG ABC & Math SG & $5.28 * *$ & 0.79 & & $4.98^{* *}$ & 1.25 \\
\hline D Math HG DEF & Math SG & 0.84 & 0.85 & & 0.94 & 1.34 \\
\hline D PSHG & & $3.40^{* *}$ & 0.51 & & $3.40^{* *}$ & 0.82 \\
\hline Age & & -0.41 & 0.24 & -0.05 & -0.32 & 0.40 \\
\hline D Enghome & & -1.04 & 0.57 & -0.04 & -0.97 & 0.94 \\
\hline D Male & & -0.40 & 0.40 & & -0.32 & 0.64 \\
\hline D White & & $2.49 * *$ & 0.48 & 0.12 & $2.62^{* *}$ & 0.80 \\
\hline D HRD & & 0.25 & 0.78 & 0.07 & 0.21 & 1.31 \\
\hline D DET & & 0.01 & 1.12 & 0.46 & -0.01 & 1.86 \\
\hline D Commerce & & -0.66 & 1.00 & & -0.17 & 1.59 \\
\hline Course repeated & & $-2.57 * *$ & 0.40 & & -0.01 & 0.68 \\
\hline D Pass Test 1 & & & & $1.23^{* *}$ & & \\
\hline IMR & & & & & $-16.9^{* *}$ & 5.80 \\
\hline D Year 2004 & 2003 & $-1.97 *$ & 0.51 & & $-3.85^{* *}$ & 0.83 \\
\hline D Year 2005 & 2003 & $1.22 *$ & 0.47 & & -0.03 & 0.77 \\
\hline Constant & & $37.5^{* *}$ & 5.47 & 2.26 & 32.7 & 9.00 \\
\hline $\mathrm{R}^{2}$ & & 0.234 & & & & \\
\hline F-stat. & & $51.7^{* *}$ & & & & \\
\hline Wald $\mathrm{Chi}^{2}(16)$ & & & & & $252.4^{* *}$ & \\
\hline Observations & & 2726 & & 2792 & 2726 & \\
\hline
\end{tabular}

Notes:

1 OLS estimation excluding students who did not write the final examination.

2 Probit estimation for the first part of the Heckman two-part procedure.

${ }^{3}$ OLS estimation for the second part of the Heckman two-part procedure

** and $*$ Statistical significance at $1 \%$ and $5 \%$ levels, respectively.

The coefficients for the ECO1010H dummy (equations 1 and 3) are statistically insignificant $(\mathrm{p}>0.10)$. This finding suggests that the educational interventions in both the first- and second-year microeconomics courses in combination had no discernable effect on the academic performance of the academic development cohort, relative to the mainstream cohort, conditional on the control variables.

Table 5 shows the results of the estimations for the second period with workshop attendance added as an additional independent variable. In this way it is possible to isolate the effect of workshop attendance on students' academic performance in ECO2003F. 


\begin{tabular}{|c|c|c|c|c|c|c|}
\hline Variable & Base cases & $\begin{array}{c}\text { (1) } \\
\text { OLS }^{1}\end{array}$ & $\begin{array}{c}\text { (1) } \\
\text { Std Err }\end{array}$ & $\begin{array}{c}(2) \\
\text { Probit } \\
\text { WRITE }\end{array}$ & $\begin{array}{c}(3) \\
\text { OLS }^{3}\end{array}$ & $\begin{array}{c}(3) \\
\text { Std Err }\end{array}$ \\
\hline D $1010 \mathrm{H}$ & & $-3.13 * *$ & 0.97 & & $-3.52^{*}$ & 1.52 \\
\hline D WSHOP & & $0.49^{* *}$ & 0.15 & & $0.54 *$ & 0.24 \\
\hline Adjmatpt & & $0.94 * *$ & 0.07 & & $0.97 * *$ & 0.11 \\
\hline D Eng FL HG & Eng SL HG & 0.41 & 1.02 & & 0.88 & 1.64 \\
\hline D Math HG ABC & Math SG & $5.34^{* *}$ & 0.79 & & $5.06^{* *}$ & 1.24 \\
\hline D Math HG DEF & Math SG & 0.99 & 0.85 & & 1.10 & 1.33 \\
\hline D PSHG & & $3.41^{* *}$ & 0.51 & & $3.42^{* *}$ & 0.81 \\
\hline Age & & -0.40 & 0.24 & -0.05 & -0.31 & 0.39 \\
\hline D English home & & -0.91 & 0.57 & 0.04 & -0.82 & 0.94 \\
\hline D Male & & -0.41 & 0.40 & & -0.33 & 0.63 \\
\hline D White & & $2.41^{* *}$ & 0.76 & 0.12 & $2.53^{* *}$ & 0.79 \\
\hline D HRD & & 0.08 & 0.79 & 0.07 & 0.02 & 1.30 \\
\hline D DET & & -0.39 & 1.12 & 0.46 & -0.44 & 1.84 \\
\hline D Commerce & & -0.69 & 1.00 & & -0.21 & 1.57 \\
\hline Course repeated & & $-2.57 * *$ & 0.40 & & -0.02 & 0.67 \\
\hline D Pass Test 1 & & & & $1.23^{* *}$ & & \\
\hline IMR & & & & & $-16.7 * *$ & 5.73 \\
\hline D Year 2004 & 2003 & $-1.98 * *$ & 0.51 & & $-3.85^{* *}$ & 0.82 \\
\hline D Year 2005 & 2003 & $1.20^{*}$ & 0.47 & & -0.05 & 0.76 \\
\hline Constant & & $37.2^{* *}$ & 5.46 & 2.26 & & 8.89 \\
\hline $\mathrm{R}^{2}$ & & 0.237 & & & 0.272 & \\
\hline F-stat. & & $49.5^{* *}$ & & & $59.6^{* *}$ & \\
\hline Wald $\mathrm{Chi}^{2}$ (17) & & & & $264.0^{* *}$ & & \\
\hline Observations & & 2726 & & 2792 & 2726 & \\
\hline
\end{tabular}

\section{Notes:}

${ }^{1}$ OLS estimation excluding students who did not write the final examination.

2 Probit estimation for the first part of the Heckman two-part procedure.

${ }^{3}$ OLS estimation for the second part of the Heckman two-part procedure

** and $*$ Statistical significance at $1 \%$ and $5 \%$ levels, respectively.

The coefficient for the ECO1010H dummy $(D$ 1010H) is -3.13 (equation 1 ) and is statistically significant $(\mathrm{p}<0.01)$. This result suggests that the educational interventions incorporated in the ECO1010H course did not have a positive effect on the academic performance of the ECO1010H cohort in ECO2003F conditional on workshop attendance and the other explanatory variables. The main reason for the relatively poor academic performance of the ECO $1010 \mathrm{H}$ cohort may lie in the changes made to the content of the second-year microeconomics course in 2003, which are described in section 2. In short, the first-year microeconomics course $(\mathrm{ECO} 1010 \mathrm{H})$ did not equip students with the mathematical skills required to make a success of ECO2003F. ${ }^{15}$ However, the coefficient for workshop attendance is 0.49 and is statistically significant $(\mathrm{p}<0.01)$. This implies that the students' course mark increases by 0.49 percentage points, on average, for each of the 12 workshops attended on average. This result suggests that the educational interventions, specifically the focus on improving students' understanding of mathematical concepts and the application of mathematical techniques, enabled those academic development and mainstream students who attended the

\footnotetext{
${ }^{15}$ It is noted that, in general, these findings differ from those made by Smith and Edwards (2007). They used data for a single year's cohort, a control group of students who had failed the firstsemester course in microeconomics, and the performance of students at their first attempt at the ECO2003F. In short, the two studies are not comparable.
} 
workshops to out-perform their peers, conditional on the independent variables. However, it is possible that workshop attendance is a function of the students' level of motivation. Students who are motivated to succeed may be more likely to attend the workshops; they may have achieved good results whether they attended the workshops or not. In this regard it is worth noting that the ECO1010H students who achieved higher marks in the final examination of the first-year microeconomics course tended to attend more of the ECO2003F workshops. ${ }^{16}$ This finding may suggest that it is the more academically able academic development students who are more likely to attend the workshops.

We included the quadratic terms, $A$ djmatpt ${ }^{2}, W S H O P P^{2}$ and $A G E^{2}$ in our second period estimation to estimate the returns academic ability, workshop attendance and age. We also included the interaction term, D 1010H*WSHOP, to compare the academic performance of the ECO1010H cohort, who attended the workshops, with the academic performance of the mainstream cohort, who did not attend the workshops.

There are increasing returns to age (0.10) and academic ability (0.02), and diminishing returns to workshop attendance (-0.02). All three results, however, are statistically insignificant $(\mathrm{p}>0.10)$. The coefficient for the variable, $D 1010 H^{*} W S H O P$, is -0.01 , but statistically insignificant $(\mathrm{p}>0.10)$. This result suggests that the $\mathrm{ECO} 1010 \mathrm{H}$ cohort, who attended the workshops, did no better than mainstream students, who did not attend workshops, conditional on the independent variables, which include the variables, $D$ $1010 H$ and WSHOP.

Looking at the other variables, the results are generally consistent with Smith and Edwards' (2007) findings. A background in mathematics (HG) improves academic performance. For example, students who achieved an A, B or C in mathematics $(\mathrm{HG})(D$ Math $H G A B C$ ) scored, on average, 2.67 percentage points more in the first period than students who had done mathematics (SG). The size of the coefficient increases to 5.34 percentage points in the second period. This finding is consistent with the fact that the course content became more mathematically orientated in the second period. Similarly, the coefficient for physical science (HG) (D PSHG) increased from 2.16 to 3.41 percentage points. The coefficient for the adjusted matriculation points score averages 1.00; a one point increase in the adjusted matriculation points score results in a one percentage point increase in the final course mark, on average, conditional on the independent variables. As in the Smith and Edward's (2007) study all these results are statistically significant $(\mathrm{p}<0.01)$.

Turning to the remaining variables, the coefficient of English home language $(D$ Enghome) is positive in the first period and negative in the second period, but statistically insignificant ( $p>0.10)$. In previous studies (Edwards 2000, Smith and Edwards 2007, Smith 2009) contradictory results have also been obtained for this variable. The coefficients for male are also statistically insignificant $(\mathrm{p}>0.10)$. Students who would have been previously classified as "white" enjoy an average premium of 2.55 percentage points. The type of school attended does not seem to be an important factor in determining performance conditional on the other independent variables. The coefficient for the inverse Mills ratio (IMR) is negative in both periods. It is statistically insignificant

16 The mean mark achieved in first-year microeconomics by the academic development students who attended between seven and 12 workshops is $62.7 \%$, between one and six workshops, $58.2 \%$, and no workshops, $56.4 \%$, and the correlation coefficient is 0.25 . 
$(p>0.10)$ in the first period and statistically significant $(p<0.01)$ in the second period. This suggests that excluding those students who did not write the final examination from the estimations only leads to a biased set of results in the second period. That said, the Heckman is not particularly well specified as there is only one exclusion restriction, whether the student passed test 1, or not. Also, the generation of a robust set of findings depends on a number of conditions being met as regards the data (Heckman 1979), which is often not the case. Given that relatively few students did not write the final examination, and that the OLS and Heckman two-part estimations give a similar set of coefficients for the key independent variables, we are of the view that the best approach may be to rely on the OLS estimation that only includes students who wrote the final examination.

Finally, the $\mathrm{R}^{2}$ 's vary between 0.234 and 0.246 . This implies that at least $23.4 \%$ of the variation in the final course mark is explained by the independent variables included in the estimations. This also suggests that there are omitted variables that may have a significant role in explaining the variation in the final course mark.

\section{(b) Effect of the interventions on pass rates}

In this section the effect of the premium earned by the ECO1010H cohort in the first period, and by those students who attended the workshops in the second period, on the overall pass rate in ECO2003F, is calculated.

Table 8 shows the effect of the premium of 2.15 percentage points (table 3 , equation 1 ) on the pass rate for the ECO1010H cohort in ECO2003F in the first period. ${ }^{17}$

\begin{tabular}{lcc} 
Table 8. Pass rates for the ECO1010H cohort for 2000-2002 \\
\hline & Total & Percentage \\
Number of students & 306 & 100 \\
$\begin{array}{l}\text { Pass (premium of 2.15 } \\
\text { percentage points) }\end{array}$ & 191 & 62.4 \\
Pass (no premium) & 156 & 51.0 \\
\hline
\end{tabular}

The average pass rate for the three-year period is $62.4 \%$. However, if these same students had attended the ECO1010F course, they would not have enjoyed a premium of 2.15 percentage points, and their pass rate would have fallen to $51.0 \%$. In other words, 35 students may be said to have passed the course they otherwise would not have passed. This represents $11.4 \%$ of the cohort.

In the second period 279 students, who had completed ECO1010H, could attend one or more of the 12 workshops offered per semester. ${ }^{18}$ Between them they attended 1054 workshops; an average of 3.8 workshops per student. The premium per workshop is 0.49

\footnotetext{
${ }^{17}$ We ran quantile estimations for the $20^{\text {th }}, 40^{\text {th }}, 50^{\text {th }} 60^{\text {th }}$ and $80^{\text {th }}$ percentiles to check the magnitude of the educational interventions on the weakest, average and strongest students. In all cases the coefficient of the ECO1010H variable is positive and statistically insignificant $(p>0.10)$ from 2.15.

1824 students from the mainstream cohort also attended one or more of the workshops. We also estimated the effect of workshop attendance on the academic performance of the ECO1010H cohort only, conditional on the same selection of independent variables. The coefficient for WSHOP is positive $(0.56)$ and statistically significant $(\mathrm{p}<0.01)$.
} 
percentage points (table 5 , equation 1$)^{19}$. Therefore, the average premium per student is 1.86 percentage points. Table 9 shows that the effect of the removal of the workshop premium is to reduce the pass rate from $66.7 \%$ to $50.9 \%$. Further, if each student had attended 12 workshops the premium would have increased to 5.88 percentage points and the pass rate to $71.3 \%$; a difference of 20.4 percentage points relative the pass rate in the absence of workshops. ${ }^{20}$

\begin{tabular}{lcc} 
Table 9. Pass rate for the ECO1010H cohort for $2003-2005$ \\
\hline & Total & Percentage \\
Number of students & 279 & 100 \\
$\begin{array}{l}\text { Pass } \\
\text { No workshops attended } \\
\text { (no premium) }\end{array}$ & 142 & 50.9 \\
$\begin{array}{l}\text { Pass } \\
3.8 \text { workshops attended } \\
\text { (premium of } 1.86\end{array}$ & 186 & \\
percentage points) & & \\
$\begin{array}{l}\text { Pass } \\
12 \text { workshops attended } \\
\text { (premium of } 5.88 \\
\text { percentage points) }\end{array}$ & 199 & \\
\hline
\end{tabular}

We suggest that relatively small increments in the course mark have a disproportionate effect on the pass rate achieved by the ECO1010H students as they lack the requisite skills to achieve above-average results.

The results of the OLS estimations lend some support to the view that ECO1010H contributes positively towards academic performance in ECO2003F in the first period. This suggests that the educational interventions incorporated in the ECO1010H course; to improve students' learning, English language, writing, quantitative and study skills, may have played a positive role in improving students' academic performance in the second-year microeconomics course. In particular, the relatively small premium earned by the ECO1010H cohort enabled them to increase their pass rate by 11.4 percentage points.

Further, the results suggest that workshop attendance, in the second period, enabled the academic development and mainstream cohorts to overcome some of the disadvantages they experienced in respect of their relative under-preparedness in mathematical techniques and applications. We suggest that the reason for the statistical insignificance $(\mathrm{p}>0.10)$ of the ECO1010H dummy in the second period is that the ECO1010H course no longer prepared students for the more mathematically orientated second-year microeconomics course. Also, too few of the academic development students attended the workshops, and of those that did, too many attended relatively few workshops. ${ }^{21}$

\footnotetext{
${ }^{19}$ We ran quantile estimations for the $20^{\text {th }}, 40^{\text {th }}, 50^{\text {th }} 60^{\text {th }}$ and $80^{\text {th }}$ percentiles to check the magnitude of the educational interventions on the weakest, average and strongest students. With the exception of the $20^{\text {th }}$ percentile estimation the coefficient of the workshop variable is positive and statistically insignificant $(\mathrm{p}>0.10)$ from 0.49 .

20 As noted above there are diminishing returns to workshop attendance, but the coefficient is relatively small $(-0.10)$ and statistically insignificant $(\mathrm{p}>0.10)$.

21102 of the 279 students making up the ECO1010H cohort, or $36.6 \%$, did not attend a single workshop.
} 


\section{CONCLUSION}

In this paper the effectiveness of educational interventions in first- and second-year microeconomics courses on the academic performance of academic development students in the second-year microeconomics course is investigated.

Three sample-selection problems are identified. The first is the selection of students into the first-year academic development microeconomics course, ECO1010H. The second is the selection into the second-year mainstream microeconomics course, ECO2003F. Finally, there is the problem that not all students who start ECO2003F get to write the final examination. The Heckman two-part procedure is used as a method to deal with the latter problem.

The use of the Heckman two-part procedure, the tracking of students through their second-year microeconomics career, and the pooling of cohorts, results in a more robust set of findings than is previously the case. Multivariate analysis is used as means to control for the effect of a selection of independent variables on the value of the dependent variable.

To the extent that the academic development cohort out-performed the mainstream cohort in the first period, conditional on the independent variables, it is possible to conclude, leaving aside the sample-selection problems, that the educational interventions included in the academic development course $(\mathrm{ECO} 1010 \mathrm{H})$ had a positive impact on students' academic performance in the second-year microeconomics course $(\mathrm{ECO} 2003 \mathrm{~F})$. Although the premium is relatively small it has the effect of raising the ECO2003F pass rate of the ECO1010H cohort by some 11 percentage points. The results also suggest that, leaving aside the sample-selection problems, the educational interventions included in the ECO1010H and ECO2003F courses did not improve the academic performance of the academic development cohort, relative to the ECO1010F cohort, in the second period. Firstly, the educational interventions included in the ECO1010H course did not enable students to cope with the increased mathematical nature of the second-year course. Secondly, too few students attended the voluntary workshops that were introduced to improve their competence in applying mathematical techniques. However, the results do suggest that for each workshop attended by academic development and mainstream students their final course mark increased by 0.49 percentage points, on average, conditional on the independent variables. This translates into an average premium of 1.86 percentage points and an improvement in the pass rate for the $\mathrm{ECO} 1010 \mathrm{H}$ cohort of some 16 percentage points. However, the results also suggest that the workshops did not improve the academic performance of the ECO1010H cohort, who did attend the workshops, relative to the mainstream cohort, who did not attend the workshops.

The key variables that may explain the relative success of the educational interventions included in $\mathrm{ECO} 1010 \mathrm{H}$ in the first period are the tutorials in economics, and language and communication, and the module designed to develop students' quantitative and graphical skills. The time that students spent in the workshops honing their ability to use mathematics in economic applications may have been beneficial in improving students' performance in the second-year microeconomics course.

It is fair to say that research of this nature is bedevilled by a variety of sample-selection problems. Therefore, these results should be treated with due circumspection. 


\section{REFERENCES}

EDWARDS, L. (2000). An econometric evaluation of academic development programmes in economics. South African Journal of Economics, 68 (3): 455-483.

BONG, M. (1996). Problems in academic motivation research and advantages and disadvantages of their solutions. Contemporary Educational Psychology, 21: 141-165.

ENTWISTLE, N. (1998). Improving teaching through research on student learning, in University teaching: international perspectives, ed. J.J.F. Forest, Ch. 4: 73-112. New York.

MCCONNELL, C. (1980). Economics 101: Where do we stand? Journal of Economic Education, 12 (1): 15-22.

PARK, K.H. and KERR, P. (1990). Determinants of academic performance: A multinomial approach. Journal of Economic Education, 21 (2): 101-111.

PARKER, K. (2006). The effect of student characteristics on achievement in introductory microeconomics in South Africa. South African Journal of Economics, 74 (1): 137-149.

(2007). Correcting for sampling bias in education production functions. South African Journal of Economics, 75 (1): 118-124.

RAIMONDO, H.J., ESPOSITO, L. and GERSHENBERG, I. (1990). Introductory class size and student performance in intermediate theory courses. Journal of Economic Education, 21 (4): 369-381.

SCOTT, I., N. Yeld and J. Hendry. (2007). A case for improving teaching and learning in South African higher education. HE Monitor 6 (October).

SMITH, L.C. (2004). A multivariate evaluation of mainstream and academic development courses in firstyear microeconomics at the University of Cape Town: A comparative study. Unpublished Masters dissertation, School of Economics, University of Cape Town.

$\longrightarrow$ and EDWARDS, L.E. (2007). A multivariate evaluation of mainstream and academic development courses in first-year microeconomics. South African Journal of Economics, 75 (1): 99-117.

(2009). An analysis of the impact of pedagogic interventions in first-year academic development

and mainstream courses in microeconomics. South African Journal of Economics, 77 (1): 162-178.

TAY, R. (1994). Students' performance in economics: Does the norm hold across cultural and institutional settings? Journal of Economic Education, 25 (4): 291-301.

TERREBLANCHE, S. (2002). A History of Inequality in South Africa 1652-2002. University of Natal Press, Scottsville and KMM Review Publishing, Sandton.

VAN DER MERWE, A. (2006). Identifying some constraints in first year economics teaching at a typical South African university of technology. South African Journal of Economics, 74 (1): 150-159.

VAN WALBEEK, C. (2004). Does lecture attendance matter? Some observations from a first-year economics course at the University of Cape Town. South African Journal of Economics, 72 (3): 11-32. 